\title{
Minha casa não é minha e nem é meu esse lugar ${ }^{1}$ : memórias dos idosos ao relento de abrigos de luxo ${ }^{2}$
}

\author{
Sandra Maia-Vasconcelos ${ }^{3}$ \\ Débora Maria da Costa Oliveira ${ }^{4}$
}

Resumo: Os idosos, nos últimos anos, ganharam espaço nas atividades sociais e na pesquisa acadêmica, pois sua perspectiva de vida foi aumentando ao longo dos anos, seja pela Medicina ou pelas condições de preservação da saúde ao longo da vida. Mas os idosos ainda enfrentam o problema da solidão na velhice, em grande parte das famílias, em todo o mundo. Embora este artigo não se pretenda ser estatístico, arriscamos relatar aqui, em primeiro plano, as histórias de pessoas idosas de mais de 70 anos de idade, que são colocadas por suas famílias em casas específicas para idosos, mostrando como elas vivenciam essa transição de sua casa para essa casa coletiva, levando em conta as diferenças de entendimento que têm sobre as variáveis família, domicílio, propriedade, objetos, pertencimento e perda. Estabelecemos um estudo comparativo entre duas casas de acolhimento para as pessoas idosas: uma na França e uma segunda no Brasil, ambas instituições mistas - público-privadas. Para a análise das histórias coletadas para esta pesquisa, utilizamos as perspectivas de Roland Barthes (2018) de narratologia, os conceitos de memória de Ricoeur (2007) e Halbwachs (2013), as definições de resiliência de Cyrulnik (2001) e de hardening de Maia-Vasconcelos (2003). A metodologia de abordagem dos sujeitos foi a abordagem dialógico-narrativa entre Lani-Bayle (2018) e Maia-Vasconcelos (2016). Nossa hipótese sobre a categoria de hardening foi confirmada pelos discursos das idosas: mesmo em situações aparentemente inteiramente favoráveis, ambas sofreram o choque da separação de seus ambientes e permanecem no espaço-tempo da ruptura, de onde olham toda sua vida.

Palavras-chave: Memória; Abordagem dialógico-narrativa; hardening; Idosos.

\footnotetext{
${ }^{1}$ Em referência à canção de Milton Nascimento e Fernando Brant: Travessia.

${ }^{2}$ Embora não sejam instituições luxuosas no real sentido da palavra, escolhemos esse termo a fim de confrontar com o sentido de abandono a que as idosas se sentiam deixadas.

${ }^{3}$ Universidade Federal do Ceará. Professora Doutora Associada do Programa de Pós-Graduação em Linguística. sandramaiafv@gmail.com.

${ }^{4}$ Universidade Federal do Ceará. Graduanda do curso de Letras - Português/Francês e bolsista FUNCAP pelo Programa Institucional de Bolsas de Iniciação Cientifica. deboraholanda@alu.ufc.br
}

Gláuks: Revista de Letras e Artes - jan/jun. 2019 - Vol. 19, $N^{o} 1$ 


\section{Introdução}

Je ne voulais pas que quiconque meurt comme Eva, seul...

Je rêvais du jour où les besoins des gens seraient prioritaires ${ }^{5}$.

Elizabeth Kübler-Ross

A pesquisa em histórias de vida é caracterizada como uma modalidade de estudo de abordagem qualitativa. Neste tipo de abordagem metodológica, o que conta é a narrativa que se faz da vida contada pela pessoa que viveu e do ponto de vista desse sujeito que relata. $\mathrm{O}$ objetivo deste tipo de estudo é apreender e compreender a vida tal como ela é contada e interpretada pelo próprio autor/sujeito na sua posição de ator de sua história. Neste caso, como pesquisadora, não procurei confirmar a autenticidade/veracidade dos fatos expressos pelas participantes; o que interessou foi o ponto de vista das contadoras de histórias. O método utilizado em história de vida procura compreender os elementos gerais contidos nas entrevistas colhidas junto às pessoas, sem se opor a analisar peculiaridades históricas. Entretanto, quando se trata de particularidades íntimas, não cabe ao pesquisador a conferência dos fatos, mas a escuta e a análise da construção verbal e não-verbal, da narrativa do sujeito que conta. Gestos são, muitas vezes, reveladores de narrativas não-ditas. Cabe ao pesquisador tomar nota e deixar claras suas observações, tentando não levantar suposições erradas.

A narrativa tem uma função descritiva e de avaliação, porque quando relatamos um fato, temos a oportunidade de refletir sobre este fato, refletir no sentido de flexão, nos dobramos para a memória. Portanto, neste tipo de abordagem, o pesquisador tem em conta o relato do sujeito e acredita no que este sujeito diz. Assim, não há nenhuma avaliação no sentido estrito da atribuição de valor pelo pesquisador, mas pelo sujeito. Sujeito e pesquisador são, assim, complementados e modificados em uma relação dinâmica, em constante construção de sentidos.

Este estudo é parte de uma pesquisa $^{6}$ maior sobre as relações familiares e institucionais, que está sendo desenvolvida na Universidade Federal do Ceará, em conjunto

\footnotetext{
${ }^{5}$ Eu não queria que ninguém morresse como Eva, sozinha ...Sonhei com o dia em que as necessidades das pessoas seriam uma prioridade.

${ }^{6}$ Relações intergeracionais em discursos: desafios e perspectivas em instituições de apoio à vida. Projeto registrado na UFC/ CNPQ/DGP/PRPPG.
}

Gláuks: Revista de Letras e Artes - jan/jun. 2019 - Vol. 19, $N^{o} 1$ 
com a Universidade Federal de Santa Catarina, da qual aqui fazemos um recorte de amostras. A pesquisa guarda-chuva abrange estudantes de graduação, pós-graduação e voluntários institucionais e se dirige a um público de crianças até idosos em situação de dificuldades diversas. Nossa abordagem é por meio da narrativa de experiência, ou dialógico-narrativa. Para o presente artigo, fazemos um recorte para uma análise das narrativas dos idosos atravessada pelo poema em prosa de Fabíola Simões (2017) intitulado "O que a memória ama torna-se eterno". Nosso panorama teórico aqui se restringe aos conceitos de memória segundo Ricoeur (2007) e Halbwachs (2013), e nosso olhar se concentra nas reflexões sobre narrativa de Barthes (2018), Maia-Vasconcelos (2003) e Lani-Bayle (2018).

\section{Memória e Narrativas de vida}

Iniciamos a questão da narrativa pelo que Ricoeur considerou ser a memória. Inicialmente e de maneira genérica, falemos de apropriação da história, pública ou privada, ou, como diria o filósofo, uma reapropriação do passado histórico. Para Ricoeur (2007), a priori, a memória é característica - em concordância com Aristóteles, “do passado". Desse modo, a memória está marcada por três traços fundamentais e paradoxais: a presença, a ausência e a anterioridade. O que significa que a imagem-recordação está presente no espírito como alguma coisa que já não está lá, mas esteve um dia e permanece na lembrança. Então, se as perdemos de vista, podemos reencontrá-las pela rememoração. Ao longo de toda sua obra, Ricoeur defende que a memória provoca um viés particular ao objeto rememorado, porque nos permite seja inserir detalhes que talvez não lhe pertencessem, seja mudar a ordem da existência das coisas tais como aconteceram. Pela memória alcançamos novos caminhos para aquilo de que nos lembramos, uma vez que o ponto de vista agora está no presente. Ao discutir sobre a noção de verdade, Ricoeur (1968) não descarta uma representação fiável de historicidade da memória e da sua relação com a história, justamente porque a associa fortemente à criação da história com a escrita. A verdade do saber histórico, para Ricoeur

Gláuks: Revista de Letras e Artes - jan/jun. 2019 - Vol. 19, $N^{o} 1$ 
(1968), oscila, muitas vezes, entre o conhecimento e a experiência. O filósofo francês cita os testemunhos de inúmeros sobreviventes da segunda grande guerra como exemplo, em especial aqueles que se tornaram literatura, artigos, arquivos escritos, partilhas narrativas, tais como o célebre Journal de Anne Frank ${ }^{7}$. São todas narrativas fiáveis, embora a História, com H maiúsculo não tenha a mesma desenvoltura ou a mesma construção "graciosa", ao mesmo tempo que tais narrativas não advoguem pelo "dever de memória" nem se massacrem pelos "usos e abusos do esquecimento" (RICOEUR, 1968; 28-29).

A abordagem de narrativa de vida é uma modalidade utilizada em particular por aqueles que trabalham no campo dos estudos de educação e saúde, mas também vem sendo aplicada como método de ensino de leitura ${ }^{8}$ e como método terapêutico ${ }^{9}$. Ensaio de Helena, Tatiana Piccardi, de autoria da professora de Filologia e Língua Portuguesa na Universidade Federal de São Paulo, é um exemplo disso. A autora descreve em sua obra a dor de perder uma filha com câncer. Uma história tocante de uma mãe que, gradualmente, vê a vida de sua filha escorrer entre seus dedos. Escrever o ensaio foi assim como uma terapia que Piccardi encontrou para viver o que ela tinha de viver naquele momento. Piccardi escreveu, com ternura e dor, os últimos meses da vida de sua filha Helena, vítima de câncer em 1997, com a idade de 5 anos. Foi o caminho encontrado por ela para vivenciar o luto e poder viver cada momento, deixando-o gravado não só em sua memória, mas também no compartilhamento das memórias de muitos outros pais que vivem esta dor cotidiana que ela viveu e vive todos os dias.

Assim como esta autora, muitos outros pais e mães viveram e vivem esta dura realidade cotidianamente. Muitos escreveram e publicaram seus escritos sobre suas vivências de sofrimentos, destacando uma experiência que toca a memória do outro. Halbwachs (2013) defende em seus estudos que não existe uma memória específicamente individual, pessoal, que não se permeie com a memória social ou coletiva. Consoante nos afirma Halbwalchs (2013; p. 26): “nossas lembranças permanecem coletivas [...] mesmo que se trate de

\footnotetext{
${ }^{7}$ Conf. FRANK, A. O diário de Anne Frank. Edição integral. Rio de Janeiro: Ed. Record, 2000.

${ }^{8}$ Conf. LOPES, M.R.R. Possibilidades subjetivas da prática da leitura para leitores idosos de Fortaleza-CE, Dissertação de Mestrado. Unifor: 2018; ROCHA, F. C. O texto autobiográfico na sala de aula: uma proposta de ensino da produção escrita para alunos do $9^{\circ}$ ano. 2016. Dissertação (Mestrado em Mestrado Profissional em Letras) - Universidade Federal do Ceará. ${ }^{9}$ Conf. MAIA-VASCONCELOS, S. Clínica do Discurso: a arte da escuta. Fortaleza: Primus, 2005; LANI-BAYLE, M. A criança e sua história: por uma clínica narrativa. Trad. Maria Passeggi e Sandra Maia-Vasconcelos. Natal: EDUFRN, 2018 .
}

Gláuks: Revista de Letras e Artes - jan/jun. 2019 - Vol. 19, $N^{o} 1$ 
acontecimentos nos quais só nós estivemos envolvidos". Essa permanência se explica pelo fato de que estamos em constante contato com o mundo a nosso redor e em constante permeabilidade social, tal como tratei em trabalho anterior (MAIA-VASCONCELOS, 2003). Somos sempre atravessados pela vida social e a atravessamos o tempo inteiro. Recentemente, tratei esse atravessamento como ondulação teleológica (MAIA-VASCONCELOS, 2018), por acreditar que de uma maneira ou de outra somos sempre tocados pelos acontecimentos do mundo exterior, porque nunca somos exteriores ao mundo. Isso retoma o conceito de Halbwachs acerca das formas de recordar de uma ou de outra pessoa, de um ou de outro lugar ou cena: nada tem exatidão a não ser pelo olhar conjunto do social, das circunstâncias e da época em que se localizam. Então, a história nos permeia e nos vemos sempre girando em torno dos fatos do mundo, o que levou Halbwachs a denominar a memória histórica de memória coletiva.

Cada um de nós sente essa memória coletiva quando lê um texto e, de repente, sente a impressão de que o autor escreveu para si. Sem sombra de dúvidas, carregamos em nós memórias que não esmaecem jamais, pois a memória não depende de nós. E nós podemos nos questionar: como é possível que este autor que não me conhece tenha o mesmo sentimento que eu? Como ele pôde passar por essa mesma situação? Por que certas memórias se cruzam e se eternizam em nós? Como é possível que alguém tenha o poder de entender tanta coisa que vem de mim?

Neste ponto, somos cruzados pelo texto literário de Fabíola Simões (2017), de onde extraímos o excerto: "quanto mais vivemos, mais eternidade ${ }^{10}$ nós criamos em nós mesmos". Eternidades que não vêm somente na idade adulta, mas também na velhice, lugar onde a criança não sabe ainda que vai chegar, ou pelo menos não percebe a dimensão temporal que a separa de lá. Uma amiga francesa, em uma conversa informal, enquanto eu lhe falava de minha pesquisa, me relatou que seu irmão, quando criança, cerca de 60 anos atrás, quando soube que um certo Sr. Dupont, o melhor confeiteiro de sua pequena cidade na França, estava em um lar para idosos em sua vizinhança, disse a sua mãe: "mãe, quando eu ficar velho, eu vou para o lar de idosos onde está o Sr. Dupont, pois assim eu vou poder comer os biscoitos que ele faz todos os dias".

\footnotetext{
${ }^{10}$ Eternidade: tempo sem fim. Tempo atemporal. Conf.: BUNGE, M. Dicionário de Filosofia. Tradução de Gita K. Guinsburg. São Paulo: Perspectivas, 2002. (Coleção Big Bang).
}

Gláuks: Revista de Letras e Artes - jan/jun. 2019 - Vol. 19, $N^{o} 1$ 
Isso me parece o oposto da imagem que discutimos aqui. O reverso da memória é a projeção da escala de tempo. Algo que eu chamaria de anti-conceito de Memória, se pensamos ao conceito de Ricoeur sobre memória refletir o passado e a expectativa do garoto se trata de uma lembrança do que ainda não foi. Quem, quando criança, não chorou por medo de que sua mãe morresse ou de que o abandonasse? Quantos daqueles que choraram na infância, ao se tornarem adolescentes e adultos, não deixaram sua mãe sozinha em casa ou em lares para idosos mais tarde? A dimensão de tempo-memória é um vazio que ainda requer muita discussão, já que tudo funciona pelo discurso e pela narrativa, mas por ora ousamos afirmar que há uma contra-conceitualidade entre memória e projeção, já que um se refere ao passado e outro ao futuro. Discussão que merece mais tempo e aprofundamento.

Neste estudo, procuramos conhecer sobre as narrativas de vida de moradores de dois lares para idosos - instituições de previdência social para idosos, um em Fortaleza, Ceará Brasil e outro em Rezé, França - e analisá-las à luz da linguística, com base na perspectiva barthesiana, considerando especialmente este vai-e-vem entre a vida e a morte operado em seu trabalho A Câmara Clara (2018). Nós, então, trabalhamos a partir de notas tomadas durante os encontros, em nosso diário de bordo ${ }^{11}$, sem o constrangimento de gravar nossas conversas. Todas as notas tomadas foram lidas pelas idosas envolvidas. $\mathrm{Na}$ pesquisa completa, projeto guarda-chuva, estabelecemos um estudo comparativo entre as duas realidades. Apresentamos na presente pesquisa, resultados que abrangem apenas as narrativas de duas mulheres idosas, considerando uma abordagem narratológica entre resiliência e hardening, conceito que surgiu em minha tese de doutorado (MAIA-VASCONCELOS, 2003), quando percebi que os sujeitos com quem eu então lidava, adolescentes em fim de vida, apoiavam-se sobre uma resistência incontrolável que não cabia chamar de resiliência. Em língua portuguesa, o termo mais próximo que encontrei foi encruamento, mas ainda não estou convencida, pelo sentido negativo que o verbo encruar carrega. Por essa razão defini que utilizaria o termo inglês hardening.

O problema que se impõe nestes casos se revela da seguinte maneira: logo que o sujeito se vê em situações extremas, assim como o fio de aço que se dobra, como no mais simples clips, que se utiliza para prender papéis, ele sofre o processo de hardening ou

\footnotetext{
${ }^{11}$ Também utilizamos nas duas últimas sessões o diário eletrônico com ajuda do aplicativo https://e-diariodebordo.com.br/
} 
endurecimento a frio até o limite de suas forças e se torna aquilo que a situação o transforma; ou seja, este sujeito, flexível ao primeiro golpe se deixa levar pelas forças externas - às vezes internas - até o limite de si mesmo. Tentar fazê-lo viver 'normalmente' como se nada tivesse mudado, seria como desdobrar o clips, forçar sua natureza agora modificada para sempre. Isso nada mais faria que rompê-lo; moldá-lo a uma vida dita normal em uma situação inexorável ainda mais traumática que o primeiro golpe. Afirmo isso refletindo sobre todos os sujeitos de pesquisa a quem tenho me dedicado ao longo dos anos: surdos, cegos, adictos ou alcoólicos em abstinência, órfãos ou que perderam seus filhos, que têm câncer ou hanseníase... tratá-los como se nunca tivessem passado pelo que passaram ou passam não é uma solução, não é sequer uma opção. Logo que o sujeito sofre um trauma que o abate, todo o resto de sua vida estaciona naquele ponto de ruptura e, ainda que ele continue a viver, ele viverá a partir dali, olhando a vida a partir daquele ponto, do ponto de ruptura. A esse olhar, eu denominei ponto de hardening (MAIA-VASCONCELOS, 2003).

O discurso que gira em torno desses sujeitos deve ser claro e aberto. Deixá-los no silêncio tampouco resolve. Provocar suas narrativas dando-lhes o valor que a experiência de vida deles tem implica construir as quebraduras aportando os pedaços que se perderam pelo caminho. Se a vida é construída de lacunas, assim como clips de papel que jamais volta a ser um fio de aço reto, um sujeito em situação de hardening é um sujeito com suas feridas a jamais curadas e com todos os direitos de deixá-las abertas e expostas, pois é bem isso que o faz resistente.

Assim como o clips que só tem pressão se estiver bem dobrado, o sujeito, após o trauma, em minha visão, só percebe sua vida a partir desse ponto de vista. Sempre que penso nisso, lembro-me da música Naquela estação, de Caetano Veloso ${ }^{12}$, gravada por Adriana Calcanhoto, que diz "e o meu coração embora / finja fazer mil viagens / fica batendo parado / naquela estação". Cada sujeito que encontrei nas diferentes pesquisas sobre situações traumáticas que realizei ao longo de minha carreira se mostrou ter ficado parado no ponto de ruptura e olhando a vida a partir deste ponto. Não necessariamente a ruptura é um evento ruim. O nascimento de um filho é uma ruptura que nos faz ver a vida com outros olhos e doravante somente a partir da visão de pais. Advogo no sentido que o sujeito que sofre uma

\footnotetext{
12 João Donato, Caetano Veloso e Ronaldo Bastos. Naquela estação. (s.d) Disponível em: $<$ https://www.vagalume.com.br/joao-donato/naquela-estacao.html > acesso em: 11/12/2019.
}

Gláuks: Revista de Letras e Artes - jan/jun. 2019 - Vol. 19, $N^{o} 1$ 
ruptura irretornável nunca se recupera, ainda que retome suas obrigações sociais, seu trabalho, sua "vida". Ainda que ele seja visto como resiliente, defendo que este sujeito se mantém parado lá no ponto de ruptura, caminhando muitas vezes sem alma no mundo dos vivos, mas que merece ser respeitado e ouvido como tal, e que isso não o diminui como sujeito. Somente conhecendo sua história podemos compreender seu passado e seu presente.

Postulamos que a história de vida é a forma de pesquisa mais adequada como meio metodológico para a compreensão do sujeito como ser humano e social. É por meio da narrativa de vida que o narrador se preenche, obrigando-se a organizar memórias desorganizadas e suas percepções imediatas de forma coerente. Esta reflexão revela, na sua narrativa, todos os microeventos que pontuam sua vida cotidiana, da mesma forma que a duração, provavelmente comum aos grupos sociais, mas que, dentro da experiência individual, contribui para a construção social da realidade. É nesse sentido que estamos adotando a metodologia de história de vida, em especial enfocando as narrativas do eu, porque acreditamos que a narrativa do autor circunstancial - aquele que se torna autor em um momento específico e em função de uma circunstância específica (FREITAS, 2010) - tem um poder exorbitante para a compreensão do ser e, para nós, em particular, para a compreensão funcional da linguagem humana como identificação e expressão.

\section{A casa da vovó: situação no Brasil e na França}

A existência de casas de acolhimento de idosos é uma necessidade moderna, bastante relacionada ao modo de vida na era da industrialização. Devido ao aumento da expectativa de vida, proporcionado pelos avanços na medicina moderna, pelo processo de urbanização e pela redução de conflitos armados em alguns locais, os idosos conseguem viver mais tempo e com mais qualidade de vida. Juntamente a isso, a inserção da mulher no mercado de trabalho estimulou o aumento do uso de métodos contraceptivos e o planejamento familiar, diminuindo a taxa de fecundidade. Tais mudanças contribuem para a ocorrência do fenômeno conhecido como envelhecimento populacional, que atinge principalmente os países desenvolvidos.

\section{Gláuks: Revista de Letras e Artes - jan/jun. 2019 -Vol. 19, $N^{o} 1$}


Apesar de representar um avanço da sociedade atual, haja vista que a expectativa de vida das pessoas aumentou, essa transformação suscita algumas questões. Durante o processo de envelhecimento, as pessoas perdem sua utilidade como força de trabalho para o capital e se tornam socialmente vulneráveis, sobretudo devido à fragilidade que assujeita o organismo humano e retira aos poucos a autonomia conquistada na fase adulta. Como nem todos os idosos possuem famílias com condições e disponibilidade para acolhê-los, as políticas públicas acabam precisando intervir na situação dessa população. Evidentemente que isso irá variar de acordo com as condições de cada local, o que é sinalizado principalmente pelo Índice de Desenvolvimento Humano (IDH) da região.

O Brasil, por exemplo, já alcançou o número de 30 milhões de idosos, 14,6\% da população total, segundo a Pesquisa Nacional por Amostra de Domicílios de 2017, realizada pelo IBGE (2017). Por outro lado, uma projeção baseada nos dados obtidos durante o último Censo do IBGE (2010) indica que a população brasileira obteve um aumento de apenas $0,38 \%$ na passagem do ano de 2018 para 2017, um acréscimo de 800 mil pessoas. Entre 2016 e 2017, o aumento tinha sido o dobro, 1,6 milhão de pessoas, o que aponta uma desaceleração na taxa de crescimento populacional. A partir desses dados, as projeções do IBGE indicam que a taxa bruta de natalidade no Brasil, que ainda é maior que a de mortalidade, irá diminuir bastante nos próximos anos. A expectativa é de que, até o ano de 2060, a população com mais de 60 anos dobre de tamanho e represente $32 \%$ do total de brasileiros. Caso essas previsões se concretizem, até um quarto da população brasileira terá mais de 65 anos no ano de 2060.

Acompanhando o crescimento da população total, o número de idosos vivendo em asilos e casas especializadas aumentou 33\%, ou seja, passou de 45.827 no ano de 2012 para 60.939 em 2017, segundo o Ministério de Desenvolvimento Social. Entretanto, uma pesquisa realizada pelo IPEA (2011) já indicava um número bem mais alto, constatando 83 mil idosos amparados em abrigos públicos e privados. A discrepância ocorreu porque os dados recolhidos pelo Ministério do Desenvolvimento Social pertenciam apenas aos abrigos com algum tipo de convênio com o poder público. Atualmente, estima-se que pelo menos 100 mil idosos pelo Brasil já vivam nessas instituições.

$\mathrm{Na}$ contramão da demanda, o número de instituições não aumentou tanto. Chamadas oficialmente de Instituição de Longa Permanência para Idosos (ILPI), essas unidades de

Gláuks: Revista de Letras e Artes - jan/jun. 2019 - Vol. 19, $N^{o} 1$ 
acolhimento não recebem muita atenção do poder público, que nem sequer sabe exatamente a quantidade delas presentes no país. Uma outra pesquisa realizada pelo IPEA entre 2007 e 2009 localizou 3.548 instituições, entre públicas e privadas. Entretanto, o Censo SUAS de 2018, promovido pelo Ministério da Cidadania, recebeu dados de apenas 1.769 unidades de acolhimento municipais e 8 estaduais. Isso significa que não há um monitoramento detalhado das instituições de natureza privada.

$\mathrm{Na}$ França, os dados são um pouco diferentes, visto que o processo de envelhecimento populacional é mais evidente nos países europeus, apesar do fôlego proporcionado pelos processos imigratórios. Atualmente, a população com mais de 65 anos no país é estimada em mais de $20 \%$, o que já colocaria a França como um país envelhecido diante da Organização Mundial da Saúde (OMS). Entretanto, segundo uma projeção do Instituto Nacional de Estatística e de Estudos Econômicos (INSEE), a população francesa em 2050 poderá contar com até 20 milhões de pessoas idosas de um total de 74 milhões de habitantes. Isso representaria um percentual de aproximadamente $27 \%$ da população total, bem acima da proporção prevista para o Brasil em 2060.

Com sua população envelhecida, a França viu crescer a demanda por casas de repouso nos últimos anos. No país, a partir de 85 anos, a maioria das pessoas vão viver em "maison de retraite", como são chamadas as casas de repouso. Ao contrário do que ocorre no Brasil, na “maison de retraite", é mais comum os idosos terem acesso, além do tratamento e atenção de profissionais como médicos e enfermeiros, a atividades que atendam suas diversas necessidades. A França também oferece pelo menos 7.200 instituições de acolhimento, que atendem cerca de 600.000 idosos, sendo a maioria de iniciativa do poder público. Somente na região parisiense, existem mais de 1.100 casas de repouso, com custos que variam de acordo com os serviços prestados/disponibilizados.

Entretanto, nem sempre as condições são favoráveis aos envolvidos nesse trabalho, já que a austeridade fiscal disseminada por teorias econômicas modernas atingiu diversos países do globo.

A partir desses dados, tanto do Brasil como na França, podemos perceber o quanto os idosos são abandonados e esquecidos, não só pela família, mas também pela sociedade e o Estado, tendo que passar, caso tenha menos condições financeiras, por situações precárias. É

Gláuks: Revista de Letras e Artes - jan/jun. 2019 - Vol. 19, $N^{o} 1$ 
necessário, portanto, que mais pesquisas sejam realizadas, tanto para entendermos melhor a realidade dessa população, como para darmos mais visibilidade às suas demandas. Nosso trabalho ganha relevância, portanto, não apenas científica, por contribuir com os estudos da linguagem, mas também social, por proporcionar aos indivíduos situações de comunicação que lhes permitam exercer as habilidades de narrar e refletir sobre suas experiências de vida.

\section{Metodologia: um conhecimento para contar}

Depois de entrar em contato com os lares de idosos nas cidades de Fortaleza e de Rezé e decidir, em função da disponibilidade manifestada pela coordenação das duas casas, pudemos dar início à pesquisa que tínhamos proposto. $\mathrm{O}$ primeiro passo foi, naturalmente, iniciar as entrevistas com os idosos que faziam parte das acomodações dos dois lares de idosos: uma instituição privada/mista, filantrópica, sem limitação de número de vagas, com vastos salões coletivos em forma de pavilhões, banheiros coletivos, subsidiados pela Prefeitura de Fortaleza e pelos idosos residentes, geralmente de classes médias baixas e pobres, mas também com alguns quartos individuais, com banheiros completos; e outra instituição, igualmente público/privada, na cidade de Rezé, com lugares limitados a 75 pessoas idosas, com um custo médio não declarado mensalmente a esta pesquisadora, mas claramente identificada como uma instituição que oferece condições de saúde e conforto superiores à primeira, igualmente financiada pelo governo e pelos idosos residentes e suas famílias, e cujos quartos individuais têm banheiros completos. Ambas as instituições prestam assistência pessoal médica e odontológica aos residentes, por meio de um pré-contrato com um plano se saúde específico da instituição ou por meio do Sistema Único de Saúde, no caso do primeiro estabelecimento.

Como se tratava de um estudo qualitativo baseado em um procedimento de coleta de narrativas de vida, o que significa que as histórias são contadas sem um modelo de entrevista preestabelecida, não nos prendemos inicialmente tampouco a uma quantidade preestabelecida de pessoas, deixando ao acaso que as reuniões de conversação decidissem o que chamou

Gláuks: Revista de Letras e Artes -jan/jun. 2019-Vol. 19, $N^{o} 1$ 
nossa atenção durante nossas visitas de intervenção. É necessário lembrar que este estudo ainda está em andamento e que aqui estamos fazendo um recorte de nossas abordagens.

Para nos aproximarmos dos idosos, utilizamos a técnica de histórias infantis do gênero Era uma vez... descrita em um estudo precedente (MAIA-VASCONCELOS, 2016), quando trabalhamos o imperfeito lúdico, categoria desenvolvida por Pontes (2012) ${ }^{13}$. Essa técnica implica em propor a contação de histórias a partir de livros e convidar os sujeitos a contar histórias do gênero infantil, a partir do comando Era uma vez, amplamente utilizado nos contos para crianças e, a partir daí, ir inserindo modificações na história infantil com fatos de seu próprio cotidiano. A experiência parte inicialmente do pesquisador. Íamos contando a história e inserindo eventos de nosso cotidiano e aos poucos os sujeitos iam participando também, até que passavam a falar unicamente de seu cotidiano e não mais das histórias dos livros infantis.

A abordagem dialógico-narrativa é uma estratégia que visa mover-se do sensível ao inteligível, como defende Lani-Bayle (2018), e podemos acrescentar que este movimento é feito em um movimento pendular constante, mas, como em uma gangorra, se desloca nos dois sentidos ao mesmo tempo. Cada movimento do sensível ao inteligível pode transformar o sensível, e assim por diante, em uma espiral que vamos discutir novamente na sequência deste estudo.

Com base no que vimos em nossos estudos anteriores (MAIA-VASCONCELOS, 2016), o procedimento, nas abordagens com história de vida, por meio da narrativa infantil, promove uma interação mais natural, uma vez que permite aos interlocutores participar de nossos discursos, porque não abordamos em uma situação de enquete, dizendo, por exemplo, me conte sobre sua vida, mas em situações de trocas, intervindo o menos possível. É uma estratégia que encontramos nos textos bíblicos, por exemplo: quando Jesus falava nas assembleias, ele falava por meio de narrativas, as parábolas. Abordamos nossos sujeitos dentro de uma escuta sensível, atenta e atenciosa, mas sem ser passiva.

\footnotetext{
${ }^{13}$ Conf. PONTES, Valdecy de Oliveira. O pretérito imperfeito do indicativo e as perífrases imperfectivas de passado em contos literários escritos em espanhol: um estudo sociofuncionalista. 2012. 264f. - Tese (Doutorado) - Universidade Federal do Ceará, Departamento de Letras Vernáculas, Programa de Pós-graduação em Linguística, Fortaleza (CE), 2012.
}

\section{Gláuks: Revista de Letras e Artes - jan/jun. 2019 - Vol. 19, $N^{o} 1$}


Assim, tentamos escutar os testemunhos dos idosos, evitando interferir em suas falas, exceto para esclarecer alguns detalhes, quando eles mesmos nos interpelaram ou quando nos sentimos levados a estimulá-los.

É importante salientar que o envolvimento do sujeito é voluntário e que tudo o que ele nos diz sobre sua vida e as reflexões que ele faz sobre si mesmo constituem objeto do segredo da pesquisa. Isso porque o sujeito não nos conta simplesmente a sua vida; há, nesta ação, toda uma reflexão pessoal sobre como ele organiza suas frases, sobre como ele procura suas palavras. Nós não lhes fazemos nenhuma pergunta prévia; é por meio do contato que surgem as perguntas, é na conversa que aprendemos juntos a demonstrar por intermédio de expressões faciais, o interesse dirigido a tudo o que o sujeito conta sobre sua vida, porque é uma maneira de incentivá-lo a continuar com mais vivacidade sua narrativa, que geralmente vem na interseção com a história que lhe contamos.

\section{Visitas e convivialidade: sobre encontros}

Como mencionado anteriormente, as reuniões foram realizadas nos dois lares para idosos. Embora existam diferentes ambientes sociais entre as duas casas, o que resultou em um estudo comparado numa pesquisa mais ampla, abordaremos neste recorte apresentado aqui apenas uma sessão em cada uma das casas, com duas idosas, a fim de discutir uma cena comum que chamou nossa atenção a respeito das memórias de suas vidas anteriores àquele momento que elas estavam vivendo e referente às propriedades, ao sentimento de pertencimento e as suas perdas.

Nossos sujeitos foram duas idosas internas de dois lares para idosos. Ambas em perfeita saúde física, mental, psíquica e neurológica. Foram realizados 4 encontros com cada uma delas, de cerca de 30 a 40 minutos cada encontro, segundo a disponibilidade de cada uma. Nos encontros nós realizamos leitura, jogos de dama, loto, bingo, gamão ou qualquer outro jogo que elas desejassem. Fizemos uma rápida sessão de costura com uma delas, porque

Gláuks: Revista de Letras e Artes - jan/jun. 2019 - Vol. 19, $N^{o} 1$ 
um botão de sua camisa estava caindo, mas não durou mais que 10 minutos. Nesse momento ela falou bastante de sua salinha de costura em casa. Mas passemos antes a conhecê-las.

Em uma de nossas visitas a Rezé, uma senhora nos recebeu: vamos chamá-la Sra. Margot, porque ela é francesa. Ela tem 92 anos de idade e está no lar de idosos há dois anos. Esta idosa pertenceu a uma família abastada e viveu em uma posição financeira relativamente boa, e está agora em um quarto. Sua queixa diz respeito ao fato de que sua casa inteira - era uma casa de cerca de $250 \mathrm{~m}^{2}$ - agora esteja reduzida a um quarto de 16 metros $^{2}$. Sua filha, presente em todos os nossos contatos, tentava, em vão, explicar a ela que havia objetos ou amostras de objetos naquele lugar que tinham pertencido a velha senhora: um prato, uma xícara, um pequeno armário, uma poltrona, uma mesa de cabeceira, algumas fotos. A senhora se queixava e à explicação de sua filha simplesmente dá de ombros e diz, "não é nada; tiraram tudo de mim. Não tenho mais nada, já não tenho a minha casa. Nada disso se parece comigo".

Estas palavras nos fizeram pensar sobre como esta senhora lida com este sentimento de perda, não só de seu lugar, mas de sua própria identidade. Mesmo com os argumentos da filha: "mãe, o que mais você quer? É isso mesmo! Você é muito bem tratada aqui", vemos que a Sra. Margot não está se sentindo bem, não há sentimento de resiliência ligada à sua existência, embora o ambiente seja socialmente estável e adequado, bem equipado com serviços médicos, psicológicos e os recursos humanos parecem ser de muito boa qualidade.

No entanto, a Sra. Margot não se queixa diretamente do lar. Ela vê o lugar com muito bons olhos, com excelentes profissionais no serviço de assistência, ela diz que a estrutura de jardins para recreação é boa e que a comida é de excelente qualidade. Este ponto crítico em que vemos a senhora Margot, podemos considerar como o ponto de hardening, logo que o sujeito se permite apresentar suas queixas, mesmo se ele está ciente de que deve continuar na mesma situação, sem condições de mudar de vida. E sem tempo para fazer qualquer outra coisa de diferente do que aceitar sua condição. Ela está em condições sociais de excelência, numa casa de aposentados confortável, com seu quarto individual, mas infeliz. Ela observa seus antigos objetos e se fixa na sua antiga casa. Ela deseja seus tapetes, suas xícaras, seus móveis, seus quadros, não pelos objetos em si, mas pelo seu lugar. Ela estava na casa de aposentados, mas seu coração continuava batendo na sua casa. Ela resistia em aceitar a mudança, mesmo depois de dois anos.

Gláuks: Revista de Letras e Artes - jan/jun. 2019 - Vol. 19, $N^{o} 1$ 
Nosso segundo sujeito era uma mulher brasileira, a quem chamaremos a Sra. Ruthe. Também encontramos a Sra. Ruthe em uma casa cujas condições de moradia eram semelhantes às da Sra. Margot, em um quarto individual, com assistência médica e odontológica. A diferença é que a Sra. Ruthe esteve, durante nossos encontros, acompanhada por sua neta, que era muito jovem e muito menos gentil do que a filha da Sra. Margot. Sra. Ruthe não se queixava da falta de objetos, louças, joias, quadros, móveis ou tapetes, como a Sra. Margot. Porém, ela reclamava muito da falta de sua casa e de suas amigas, vizinhas com quem ela conversava na calçada da igreja, de ter um bom café no final da tarde com as amigas depois após a Missa para fofocar um pouco. Queixou-se que não poderia mais ir ao mercado: "Eu gostava de fazer as minhas próprias compras e escolher a minha própria comida, meus legumes. Agora, tudo isso chega pronto, de qualquer jeito, essas pessoas não sabem como escolher um bom tomate", ela me diz.

Ao contrário da Sra. Margot, a Sra. Ruthe não recebe visitas frequentes. Na verdade, sua neta estava com ela no dia em que fui vê-la, porque o protocolo de pesquisa exige a presença de um membro da família, mas a menina parecia muito impaciente, pois ela foi forçada por sua mãe a estar lá. Ela se mostrou várias vezes grosseira e impaciente com a avó, que finalmente a expulsou do quarto. Durante os últimos dez minutos de nossa conversa, ficamos apenas nós duas. Então eu tomei cuidado para deixar a porta aberta por segurança ética para mim e para ela.

\section{Alguns resultados para refletir em conclusão}

Mas o meu passado vive

Em tudo que faço agora

Ele está no meu presente

Roberto Carlos, O Divã.

Gláuks: Revista de Letras e Artes - jan/jun. 2019 - Vol. 19, $N^{o} 1$ 
Este estudo se inscreve em uma pesquisa maior e contínua e propõe uma análise da memória de mulheres idosas colocadas por seus familiares em residências específicas para idosos. Este momento do estudo apresenta uma análise de duas senhoras internas em dois domicílios, um no Brasil e outro na França. Os protocolos estão sendo registrados no Comitê de ética da Universidade Federal de Ceará, por isso só apresentamos aqui resultados preliminares como parte de um estudo prévio.

As mulheres idosas concordaram em participar de nossa pesquisa usando método de abordagem dialógico-narrativa, que leva em consideração a conversa pela contação de histórias aqui descrita. Para a coleta de dados, não foram utilizados meios digitais: nem gravadores, nem câmeras. Todas as informações foram anotadas no diário de bordo conforme discriminado. Nós simplesmente tomamos nota dos diálogos mantidos em seus quartos, sempre na frente de pelo menos um membro da família, com exceção da ocasião em que a neta de Sra. Ruthe saiu do aposento. Este estudo envolve uma aluna de Iniciação Científica IC/UFC, que não esteve presente na coleta das entrevistas, mas que trabalhou nas transcrições e análises, bem como na organização dos dados sobre as instituições de idosos no Brasil e na França.

Como dissemos no início, tivemos o cuidado de trabalhar com idosas que tivessem preservadas sua saúde mental e neurológica, a fim de evitar desvios em nossa análise. Nenhuma das duas idosas com quem tivemos contato sofriam de demência ou senilidade, Mal de Alzheimer ou qualquer perda neuro-sensora. Compreendemos que nossos resultados podem ser considerados fiáveis, embora não sejam exaustivos. Em se tratando de estudos qualitativos, há sempre algo mais a ser dito, pois a subjetividade pode ser sempre superada por outra subjetividade, sem perda da seriedade acadêmica.

O que podemos dizer até o momento é que as memórias das idosas envolvidas neste estudo refletem seu sentimento de pertencimento ao mundo, que estava diretamente relacionado ao seu sentimento de perda de autonomia, tal como no caso da Sra. Ruthe que reclamou que não podia mais fazer compras na feira e escolher seus legumes. Confesso que também não sei escolher um bom tomate. Dona Margot, por sua vez, se encontrava na frustração de ver rodeada de fragmentos de sua antiga casa, como alguém que se vêm sentada sobre os escombros de seu passado, sem poder voltar ao que era, sempre na perspectiva do

\section{Gláuks: Revista de Letras e Artes-jan/jun. 2019 -Vol. 19, $N^{o} 1$}


que foi um dia sua vida. Esse olhar que tenho visto nos sujeitos de minhas pesquisas, um olhar parado na estação, olhando a vida a partir do trauma, ainda que caminhando ao longo do tempo.

Vemos nas duas situações que as pessoas idosas apresentam, em suas memórias, narrativas vivas de suas vidas antes do lar para idosos. Em ambos os casos, foi possível visualizar muito claramente o que Barthes tratou como trazer a morte para a vida, "O retorno dos mortos" (BARTHES, 2018, p. 17). Abrir a lembrança pela narrativa é como revelar uma fotografia que estava em um negativo perdido no fundo de uma gaveta esquecida. Ao mesmo tempo que desenvolvemos a técnica de pesquisa com narrativas de experiência, questionamonos quais as descobertas que o sujeito e o pesquisador podem fazer sobre si mesmos. Para Barthes, uma fotografia ressuscita, pela imagem, alguém ou algo que já não está, conceito que encontra a visão de Ricoeur no paradigma da história já discutido aqui. Desse modo, estar em uma posição de acolhimento e abandono - o que eu considero estar em um lar para idosos - é, como diz Barthes (ibid., 180), "ver-se... [como] um bem restrito". Tomo essa alusão como um símbolo do que a pessoa idosa representa em nossa sociedade: meu velho passa a me pertencer e, portanto, eu faço o que eu quero dele. Então você, meu velho não tem do que reclamar uma vez que, na sua situação, como disse a filha da Sra. Margot, "o que mais você pode querer?". É tentador, mas não nos cabe aqui analisar a postura dos familiares.

Nessa perspectiva, no âmago destes resultados iniciais, nossas análises mostraram que a abordagem dialógico-narrativa foi a melhor opção para o encontro com essas mulheres idosas. Mostraram, ainda, que suas memórias nos trouxeram um testemunho de suas experiências na relação entre um antes e um agora em que a família não parece funcionar como aquilo que Cyrulnik (2001) chama de um tutor de resiliência - alguém que ampara e conduz à felicidade. As duas mulheres idosas apresentaram-se, ao mesmo tempo, bem acolhidas em seus respectivos abrigos, mas, em suas narrativas, não pareciam felizes. As fronteiras entre o passado e o presente são notáveis e promovem uma exigência de corresponsabilidade com a qual os membros da família claramente não respondem. Isso nos ajudou a perceber o sentido da urgência do seu próprio posicionamento vis-à-vis a sua própria vida, o que chamamos de hardening (MAIA-VASCONCELOS, 2003). Acreditamos, portanto, que, em uma relação dialógico-narrativa, é necessário abrir um sistema de trocas

Gláuks: Revista de Letras e Artes - jan/jun. 2019 - Vol. 19, $N^{o} 1$ 
generosas entre os sujeitos, a fim de que haja um crescimento fecundo do diálogo e um compartilhamento rico da memória.

Em ambos os casos, não houve queixas sobre as respectivas residências, muito pelo contrário, ambas as mulheres têm apenas elogios a fazer sobre seus respectivos lugares. As queixas vieram da perda de seu passado. O sentimento de incapacidade de retornar à vida de antes favorece o vazio. A pausa entre o momento desde que entraram nos lares para idosos e a consciência de que elas não vão sair dali vivas não lhes permite desenvolver uma sensação de resiliência, mas acreditamos que ambas mantêm as suas memórias fixas como um suporte para a vida. Esse suporte é o que temos chamado de hardening, a posição resistente e estática do sujeito no ponto de ruptura. O estar preso ao momento que provocou o trauma, ao passado que foi deixado, contra a vontade delas, apesar delas. A estrutura material "casa" se desloca, como todas as condições de convivialidade que as famílias puderam oferecer. Nada falta, de material, aos sujeitos envolvidos na pesquisa. Falta-lhes, no entanto, aquilo que lhes parece ser sua identidade. Embora não tenhamos aqui trabalhado sobre o tema identidade, vimos que mesmo os objetos que identificavam suas casas não fazem sentido para sua nova residência, o que pareceu incompreensível para a filha de uma das senhoras.

Tenho visto, em conversas informais, muitas críticas de pessoas a alguém que não consegue superar a morte de um ente querido ou a perda de um companheiro ou de um emprego. Essas cicatrizes que ficam escritas à flor da pele são as mesmas que se escondem sob mantas ou cabelos. Carregamos a marca do cordão umbilical por toda nossa vida, não importa quantos anos vivamos, ali está a ruptura de nossa mãe. Essas mãos que agora tremem inseguras, essas vozes que agora falham, esses olhares que pairam no nada, um dia seremos nós também. As narrativas com idosos e idosas ainda podem nos dar muitas histórias a contar; ainda há muito a dizer e ver. O aprofundamento das análises e outros encontros irão fornecernos muito mais informações que certamente nos indicarão outras pistas a seguir em nossas análises.

Gláuks: Revista de Letras e Artes - jan/jun. 2019 - Vol. 19, $N^{o} 1$ 


\section{Referências Bibliográficas}

BARTHES, R.(1980) A Câmara clara: nota sobre a fotografia. Trad. Júlio Castañon Guimarães. 7a edição. Rio de Janeiro: Nova Fronteira, 2018.

CYRULNIK, Boris et al. La Résilience: le réalisme de l'espérance. Ramonville Saint-Agne: Erès, 2001.

FREITAS, Maria Leidiane Tavares. Constituição de Autoria em Narrativas de Viajantes: Entre o Sujeito e a Designação. 2010. Dissertação de Mestrado. Programa de Pós-Graduação em Linguística da Universidade Federal do Ceará.

HALBWACHS, Maurice. A memória coletiva. Tradução de Beatriz Sidou. $2^{\mathrm{a}}$ ed. São Paulo: Centauro, 2013.

LANI-BAYLE, M. A criança e sua história: por uma clínica narrativa. Trad. Maria Passeggi e Sandra Maia-Vasconcelos. Natal: EDUFRN, 2018.

MAIA-VASCONCELOS, S. ContAção: a arte que conta a vida que conta a história. Fortaleza: EDUECE, 2016.

MAIA-VASCONCELOS, S. Penser l'école et la construction des savoirs: une étude menée auprès d'adolescents cancéreux. 500f. Tese (Doutorado em Sciences de l'Éducation) Université de Nantes, Nantes, 2003.

RICOEUR, P. História e verdade. Trad. F.A.Ribeiro. Rio de Janeiro: Forense, [1955] 1968.

RICOEUR, Paul. A memória, a história, o esquecimento. Trad. Alain François et al. Campinas, SP: Unicamp, 2007.

SIMÕES, Fabíola. Felicidade distraída. São Paulo: Novo Século, 2017.

Gláuks: Revista de Letras e Artes - jan/jun. 2019 - Vol. 19, $N^{o} 1$ 


\title{
Chez-moi est chez les autres et je ne suis de nulle part: mémoire des personnes âgées emprisonnées dans du luxe
}

\begin{abstract}
Résumé: Les personnes âgées dans les dernières années ont gagné de la place dans les activités sociales et dans les recherches, leur perspective de vie s'étant améliorée au fil des années, soit par la Médecine, soit les conditions de préservation de la santé tout au long de la vie. Mais les personnes âgées sont toujours confrontées au problème de la solitude de la vieillesse, en grande partie des familles dans le monde. Bien que cet essai ne se prétende pas statistique, nous risquons ici de mettre au premier plan les récits de personnes âgées de plus de 70 ans logées par leur famille dans des foyers spécifiques aux personnes âgées sur la manière dont ils vivent ce passage de leur domicile à ce foyer collectif, compte tenu des différences de compréhension qu'ils ont à propos des variables famille, domicile, propriété, objets, appartenance et perte. Nous avons établi une étude comparative entre deux foyers d'accueil pour les personnes âgées, un en France et un deuxième au Brésil, tous les deux étant des institutions mixtes - publiques et privées. Pour les analyses des récits récoltés pour cette recherche, nous utilisons les perspectives Barthésienne (2018) sur la narratologie, les concepts de mémoire de Ricoeur (2007) et de Halbwachs (2013), et les concepts de la résilience de Cyrulnik (2001) et de l'écrouissage de Maia-Vasconcelos (2003). La méthodologie d'approche des sujets fût l'approche dialogique-narrative entre Lani-Bayle (2018) et Maia-Vasconcelos (2016). Notre hypothèse sur la catégorie d'écrouissage a été confirmée par les discours des personnes âgées: même dans des situations apparemment tout à fait favorables, toutes deux ont subi le choc de la séparation de leur environnement et restent dans l'espace-temps de la rupture, d'où elles regardent toute leur vie.
\end{abstract}

Mots-clés: mémoire; approche dialogique-narrative; écrouissage; personnes âgées.

Gláuks: Revista de Letras e Artes - jan/jun. 2019 - Vol. 19, $N^{o} 1$ 